\title{
Development of H5 subtype-specific monoclonal antibodies (MAb) and MAb-based assays for rapid detection of $\mathrm{H} 5$ avian influenza
}

\author{
Huaguang $\mathrm{Lu}^{1 *}$, Lin $\mathrm{Lin}^{1}$, Ronghui Wang ${ }^{2}$, Yanbin $\mathrm{Li}^{2}$, Bill Scheuchenzuber ${ }^{1}$, Jiabo Liu ${ }^{3}$, \\ Zhiqin Xie ${ }^{3}$, Joseph A. Rosebrock ${ }^{4}$ \\ ${ }^{1}$ Wiley Lab/Avian Virology, Animal Diagnostic Laboratory, Department of Veterinary and Biomedical Sciences, Pennsylvania State \\ University, University Park, USA; ${ }^{*}$ Corresponding Author: hxl15@psu.edu \\ ${ }^{2}$ Department of Biological and Agricultural Engineering, University of Arkansas, Fayetteville, USA \\ ${ }^{3}$ Guangxi Veterinary Research Institute, Nanning, China \\ ${ }^{4}$ ImmTech, Incorporated, 206 High St., New Windsor, USA
}

Received 8 September 2012; revised 6 October 2012; accepted 19 October 2012

\begin{abstract}
Avian influenza (Al) virology surveillance is the most important method to monitor AI virus (AIV) in poultry so as to effectively prevent and control Al outbreaks. Monoclonal antibodies (MAb)based assays are highly sensitive and specific for AIV detection, and much practical and economic for test-in-field or onsite. Many such assays have been developed and are still in developing since the H5N1 highly pathogenic Al (HPAl) outbreaks occurred in South East Asia in 2003. A MAb-based dot-enzyme-linked immunosorbent assay (ELISA) has been developed in our lab during late 1990s and early 2000s. Meanwhile, AIV $\mathrm{H} 7$ and $\mathrm{H} 5$ subtype specific-MAbs have been successfully developed in our laboratory to enhance the Dot-ELISA and other MAb-based assays for AIV detection. Production and purification of the $\mathrm{H} 7$ and $\mathrm{H} 5$ MAbs were made to provide essential reagents for Dot-ELISA and other immunoassays, and the current development of a novel Biosensor technique for rapid detection of AIV from clinical and field specimens.
\end{abstract}

Keywords: Avian Influenza Virus; Hemagglutinin; Hybridoma Cell Line; Monoclonal Antibodies;

Dot-ELISA; Biosensor

\section{INTRODUCTION}

The H5N1 highly pathogenic avian influenza (HPAI) outbreaks occurred initially in domestic poultry and wild birds species in Southeast Asian in 2003 and soon spread to Middle East, Europe and Africa, and currently are still ongoing in poultry in a number of countries. To date, the
HPAI H5N1 virus still remains a poultry pathogen which mainly infects avian species. The H5N1 virus infections of humans are rare and most human cases have been associated with direct animal contact during poultry outbreaks. However, infection in humans is very serious when it occurs; between 2003-2011, 58\% (332/566) of human cases infected with H5N1 virus have died as documented on WHO reports [1]. Because all subtypes of AI viruses (AIV) or influenza A viruses, particularly $\mathrm{H} 7$ and $\mathrm{H} 5$ subtypes, have the ability to mutate from a low pathogenic strain to a high pathogenic strain. If they are allowed to circulate in poultry flocks, they have the ability to become highly lethal [2-4], and the HPAI H5N1 virus could be eventually mutated to a human pathogen being able to infect humans more easily and spread easily from one person to another. Therefore, it is a long term goal to continue AIV surveillance program in AIV affected countries or regions and also to continue developing much sensitive, simple, rapid, robust and reliable assays to effectively monitor AIV infections or new emerging virus strains.

Monoclonal antibodies (MAb) are powerful immunochemical tools. MAb-based diagnostic assays are highly sensitive and specific for disease detection, and much feasible and economic for test-in-field or onsite. The usefulness of MAb stems from three characteristics: their specific binding, their homogenicity, and their ability to be produced in unlimited quantities. This paper briefly describes the development and production of AIV H5 subtype-specific MAb to enhance MAb-based assays (e.g., Dot-ELISA and Biosensor) for the rapid detection of AIV.

\section{MATERIALS AND METHODS}

Virus Propagation, concentration and purification. The H5N2 virus was propagated in specific-pathogen- 
free (SPF) embryonating chicken eggs (ECE). Over 5 liters of allantoic fluids containing H5N2 virus were produced for purification and extraction of the surface hemagglutinin (HA) proteins which are specific to H5 subtypes of AIV. The H5N2 virus in allantoic fluids was concentrated to approximately 100X using Pellicon ${ }^{\circledR}$ XL Device (Millipore, 290 Concord Road, Billerica, MA, USA). Sucrose gradient centrifugation technique was utilized for purification of the virus protein. The concentrated and purified AIV H5N2 virus was used for extraction of AIV H5 subtype-specific hemagglutinin (HA) proteins for $\mathrm{H} 5 \mathrm{MAb}$ production.

Extraction of viral HA protein. Biology grade detergent of Triton X-100 (Sigma-Aldrich, Saint Louis, MO, USA) was used for extraction of HA proteins. The concentrated and purified H5N2 virus was treated with the Triton X-100 detergent and then was centrifuged at a ultra speed of 55,000 rpm for $60 \mathrm{~min}$ at $4^{\circ} \mathrm{C}$ to separate the solubilized surface glycoproteins (HA proteins) from virus core proteins. The supernate buffer contains HA proteins, and the virus cores contain nucleic proteins. After the ultra speed centrifugation, centricon-100 was used to exchange the supernate buffer by repeatedly adding a $0.02 \mathrm{M}$ phenylmethysulfonyl (PMSF) saturated phosphate-buffered saline (PBS). The extracted HA proteins were visualized by SDS PAGE electrophoresis.

Measurement of HA protein antigen for mouse immunization. A concentration of $5.66 \mathrm{mg} / \mathrm{ml}$ of the $\mathrm{H} 5$ HA proteins was obtained for inoculation to mice. Four mice were immunized with the $\mathrm{H} 5 \mathrm{HA}$ antigen in complete Freund's adjuvant. At two weeks interval, further boosts were given in incomplete Freund's adjuvant. During this regimen, 1 of 4 mice died. The mice were screened for serum antibody development during the immunization period. The mice were bled twice and serum samples were tested by ELISA assays, which indicated that the HA antigen was highly antigenic, producing a serum ELISA titer of approximately 1:60,000, with relatively low background.

Cell fusion and hybridoma production. Cell fusions for hybridoma production were done using Sp2 mouse myeloma cells and spleen cells from one of the immunized mice at one time. Colonies giving ELISA absorbance higher than control were isolated, and strong positive colonies were selected for hybridoma production.

MAb production and purification. The cloned H5 hybrid cells were injected into 16-wk-old female mice via intraperitoneal route administration. The mice had been primed 14 days prior with $0.5 \mathrm{ml}$ of pristane. Ascites fluids containing MAb harvested from the injected mice were used for MAb-based immunoassays (e.g., DotELISA, IFA, IHC) at appropriate dilutions without purification. Purified MAb were prepared from ascites fluids by Protein-G column chromatography (Virusys Corporation, MD). Briefly, Ascites was diluted in $100 \mathrm{mM}$ Tris pH 8 and applied to a Protein G-agarose column. After rinsing out the unbound sample, the $\mathrm{pH}$ was lowered by the addition of $100 \mathrm{mM}$ Glycine $\mathrm{pH}$ 3. Eluted antibody was immediately neutralized with $1 \mathrm{M}$ Tris $\mathrm{pH}$ 8. Antibody was dialyzed against PBS and quantitated by absorbance at $280 \mathrm{~nm}$. The purified AIV H5 MAb were used for the impedance biosensor system for the detection of H5 subtype of AIV, and was also chosen for evaluation as a capture antibody in an ELISA-based antigen assay that could be used for antigen detection or antibody detection.

MAb-based Dot-ELISA and Biosensor. The published procedures of Dot-ELISA developed in previous studies [5] and the novel Biosensor technique currently under evaluation studies [6,7] were used for characterization tests and utilization of the AIV H5 subtype-specific MAb for detection of $\mathrm{H} 5$ subtypes of AIV.

\section{RESULTS AND DISCUSSION}

Stock hybridoma cell lines for production of AIV subtype specific MAb to H5 and H7 HA antigens and N2 NA antigens have been successfully developed in our recent and previous research studies. Ascites fluids of the $\mathrm{H} 5, \mathrm{H} 7$ and N2 MAb were produced in mice inoculation/infection of these hybridoma cell lines. Each of these MAb specifically reacted to H5, H7 and N2 subtypes of AIV, respectively (Figure 1). Findings of MAb evaluation studies indicate that these MAb are highly sensitive and specific for the detection of their homologous subtypes of AIV by MAbs-based Dot-ELISA, indirect fluorescent antibody (IFA) test, immunohistochemistry (IHC) and Biosensor assay (Table 1). The DotELISA using H5 subtype specific MAb detected AIV H5N2, H5N3 and H5N9 subtypes of AIV stored at Wiley lab at Penn State University, and also detected the HPAI H5N1 virus in National Veterinary Diagnostic Laboratories in Lao PDR and Kingdom of Saudi Arabia.

The H5 subtype specific MAb has been applied successfully to the novel Biosensor assay for rapid detection of AIV H5N1 virus antigens in our recent research studies [6,7], and the Biosensor test results was comparable with real-time RT-PCR results. The impedance biosensor system was based on a combination of magnetic nanobeads, which were coated with the purified AIV subtype specific H5 MAb for capture (separation and concentration) of a target virus, and a microfluidic chip with an interdigitated array microelectrode for transfer and detection of target virus, and impedance measurement of the bio-nanobeads and AIV complexes (Figure 2). A linear relationship was found for the correlation between the readings from impedance change (kohm) measured by impedance biosensor and $\mathrm{Ct}$ value tested by real-time 


\begin{tabular}{|c|c|c|c|c|c|c|c|c|c|}
\hline \multicolumn{2}{|c|}{$\underline{\text { AIV Group Mab }}$} & \multicolumn{2}{|c|}{$\underline{\text { AIV H5 Mab }}$} & \multicolumn{3}{|c|}{ AIV H7 Mab } & \multicolumn{3}{|c|}{$\underline{\text { AIV N2 Mab }}$} \\
\hline $\mathrm{H} 3 \mathrm{~N} 2$ & $1+$ & $\mathrm{H} 3 \mathrm{~N} 2$ & $1-$ & $\mathrm{H} 3 \mathrm{~N} 2$ & 1 & - & $\mathrm{H} 3 \mathrm{~N} 2$ & $0^{\prime}$ & + \\
\hline H7N2 & $2+$ & $\mathrm{H} 7 \mathrm{~N} 2$ & $2-$ & $\mathrm{H} 7 \mathrm{~N} 2$ & 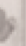 & + & $\mathrm{H} 7 \mathrm{~N} 2$ & 2 & + \\
\hline H9N2 & $0^{3}+$ & H9N2 & 3) - & H9N2 & ste & - & $\mathrm{H} 9 \mathrm{~N} 2$ & & + \\
\hline $\mathrm{H} 5 \mathrm{~N} 1$ & $24+$ & $\mathrm{H} 5 \mathrm{~N} 1$ & + & $\mathrm{H} 5 \mathrm{~N} 1$ & e & - & $\mathrm{H} 5 \mathrm{~N} 1$ & & - \\
\hline $\mathrm{H} 5 \mathrm{~N} 2$ & $3+$ & H5N2 & + & H5N2 & s. & - & $\mathrm{H} 5 \mathrm{~N} 2$ & & + \\
\hline H5N3 & + & H5N3 & + & H5N3 & & - & $\mathrm{H} 5 \mathrm{~N} 3$ & & - \\
\hline
\end{tabular}

Figure 1. Dot-LISA using AIV group, H5, H7 and N2 MAbs for detection of their AIV subtypes.

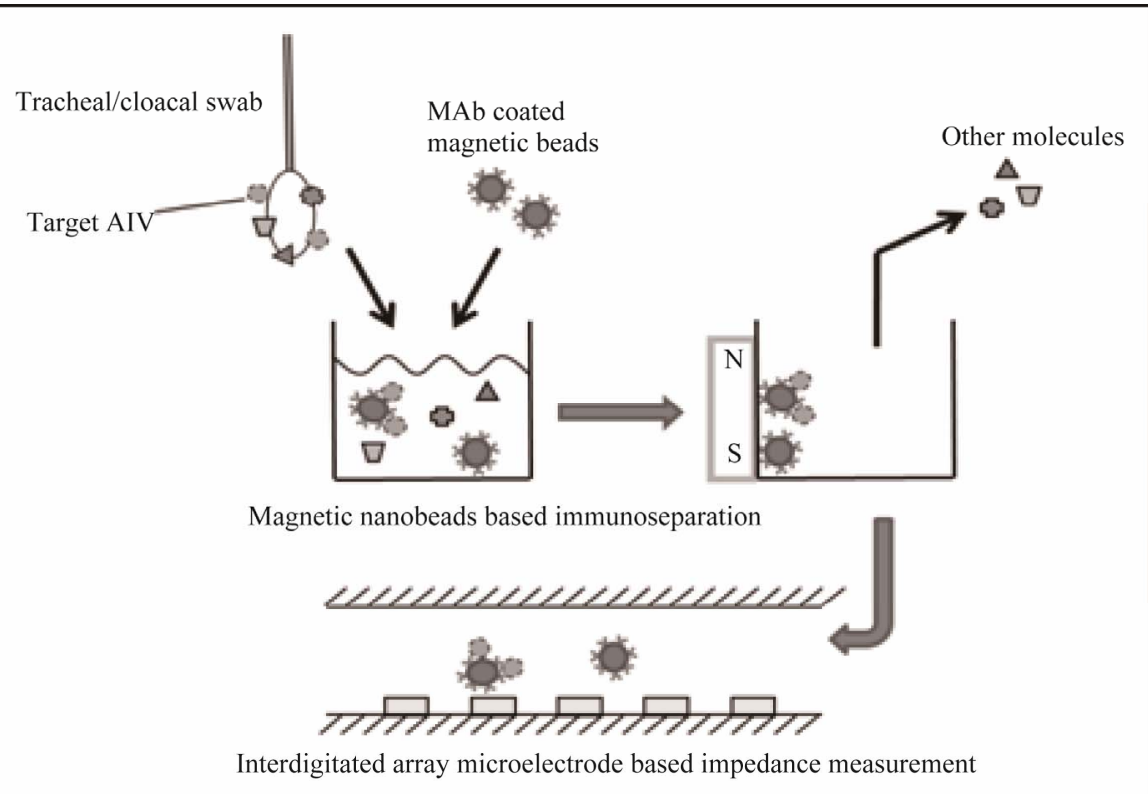

Figure 2. Principle of the impedance biosensor system for AIV detection.

Table 1. AIV H5 MAb on testing H5 and other subtypes of AIV by Dot-ELISA, Biosensor, IFA and IHC assays.

\begin{tabular}{|c|c|c|c|c|}
\hline \multirow{2}{*}{ AIV subtypes } & \multicolumn{3}{|c|}{$\begin{array}{l}\text { H5 MAb ascites fluids 1:500 } \\
\text { working dilution }\end{array}$} & \multirow{2}{*}{$\begin{array}{l}\text { purified H5 MAb ascites }(1 \sim 5 \\
\mathrm{mg} / \mathrm{ml}) 1: 200 \text { working dilution } \\
\text { Biosensor }\end{array}$} \\
\hline & Dot-ELISA & IFA & IHC & \\
\hline H3N2 & - & - & - & - \\
\hline H7N2 & - & - & - & - \\
\hline H9N2 & - & - & - & - \\
\hline H5N1 & + & Not done & Not done & + \\
\hline H5N2 & + & + & + & + \\
\hline H5N3 & + & + & + & + \\
\hline H5N9 & + & + & + & + \\
\hline
\end{tabular}

Note: The H5N1 virus was inactivated highly pathogenic avian influenza (HPAI) virus, and all other subtypes were live low pathogenic avian influenza (LPAI) viruses. 
RT-PCR in the virus titer range from $1 \times 10^{1.2} \mathrm{ELD}_{50} / \mathrm{ml}$ to $1 \times 10^{5.2} \mathrm{ELD}_{50} / \mathrm{ml}$, and a corresponding equation was described as: $y=0.49 x+32.87\left(\mathrm{R}^{2}=0.95\right)$ where $y$ is the reading of $\mathrm{Ct}$ value from rRT-PCR and $\mathrm{x}$ is the reading of impedance change (kohm) from impedance biosensor.

The purified H5 MAb was also chosen for evaluation as a capture antibody in an ELISA-based antigen assay for antigen detection or antibody detection. NUNC MaxiSorp plates were coated overnight with AIV H5 MAb at $2 \mathrm{ug} / \mathrm{ml}$, blocked, dried, and stored dessicated in a mylar pouch. Following incubation of the plates with different antigens at different concentrations, the plates were sequentially reacted with chicken antiserum produced using H5N2 or a normal chicken serum pool, HRP-labelled goat anti-chicken IgG, TMB, and TMB stop solution. The plates were then read at $450 \mathrm{~nm}$ using a Mediators $\mathrm{PhL}$ plate reader. Preliminary results with the purified H5 MAb indicates that this H5 MAb will function as a capture antibody after being coated and dried onto the surface of high binding ELISA plates. Using a variety of AIV subtype preparations (H5N2, H6N8, H4N2, H4N8, H5N9, and H5N3), a variety of hyperimmune chicken antisera (anti-H5N2, anti-H9N2, anti-H1N1, and anti-NDV), and pooled normal chicken sera, we were able to demonstrate excellent sensitivity (signalto-noise ratios $>30: 1$ ) and specificity (signal-to-noise ratios $<2: 1$ ). Improvements in specificity can be achieved by using more purified reagents for the detection component of the assay. These results support the utilization of the AIV H5 MAb for use in an ELISA format that could be used to detect $\mathrm{H} 5$ antigen or antibody.

The AIV H5, H7 and N2 subtype-specific MAbs can be effectively used for the detection of AIV by MAbbased Dot-ELISA, other immunoassays, and Biosensor system, which offer great potential as useful methods for use in routine AIV diagnostics and surveillance programs, and are feasible for test-in-field or onsite for the rapid detection of AIV infections from field specimens.

\section{ACKNOWLEDGEMENTS}

We would like acknowledge all funding sources of our research projects as the following:

Pennsylvania Poultry Industry Egg/Broiler Check-Off 2002 research Project. Project Title "Development of Group and Subtype Specific

\section{ABBREVIATION}

$\mathrm{AI}=$ Avian influenza;

AIV = Avian influenza virus;

HPAI = Highly pathogenic avian influenza;

Dot-ELISA = Dot-enzyme-linked immunosorbent assay;
Monoclonal Antibodies to Avian Influenza Virus (AIV)”.

Pennsylvania Department of Agriculture (PDA) Research Project, PDA Contract ME No. 449420. Project Title "A Longitudinal Study of a Novel Dot-ELISA for Detection of Avian Influenza Virus”.

Pennsylvania Department of Agriculture (PDA) Research Project, PDA Contract ME No. 442323. Project Title "Development of Group and Subtype Specific Monoclonal Antibodies to Avian Influenza Virus".

US Department of Agriculture, USDA/NRI Project \#2008-3520418662 and USDA/NRI Project No. 2009-35603-05063. Project Title "Nanowire Switch and Nanoelectrode/nanochannel Based Impedance Biosensor for Rapid Screening of Avian Influenza”.

\section{REFERENCES}

[1] WHO (2010) Cumulative number of confirmed human cases of avian influenza A(H5N1) reported to WHO. WHO Report.

http://www.who.int/influenza/human animal interface/H 5N1_cumulative_table_archives/en/

[2] Gardner, I.D. and Shortridge, K.F. (1979) Recombination as a mechanism in the evolution of influenza viruses: A two-year study of ducks in Hong Kong. Reviews of Infectious Diseases, 1, 885-890.

[3] Saito, T., Horimoto, T., Kawaoka, Y., Senne, D.A. and Webster R.G. (1994) Emergence of a potentially pathogenic H5N2 influenza virus in chickens. Virology, 201, 277-284. do:10.1006/viro.1994.1292

[4] Zhou, N.N., Shortridge, K.F., Claas, E.C., Krauss, S.L. and Webster, R.G. (1999) Rapid evolution of H5N1 influenza viruses in chicken $\mathrm{s}$ in Hong Kong. Journal of Virology, 73, 3366-3374.

[5] Lu, H. (2003) A longitudinal study of a novel Dot-ELISA for detection of Avian influenza virus. Avian Diseases, 47, 361-369.

doi:10.1637/0005-2086(2003)047[0361:ALSOAN]2.0.C $\underline{\mathrm{O} ; 2}$

[6] Wang, R., Li, Y., Mao, X., Huang, T. and Lu, H. (2010) Magnetic bio-nanobeads and nanoelectrode based impedance biosensor for detection of avian influenza virus. IEEE 4th International Conference, Budapest, 27 September - 1 October 2010, 214-217.

[7] Wang, R., Lin, J., Lessiter, K., Srinivasa, B., Lin, L., Lu, H., Tung, S., Hargis, B., Bottje, W., Berghman, L. and Li, Y. (2011) Evaluation study of a portable impedance biosensor for detection of avian influenza virus. Journal of Virological Methods, 178, 52-58.

http://www.ncbi.nlm.nih.gov/pubmed/21872621

Mab = Monoclonal antibodies;

SPF $=$ Specific-pathogen-free;

$\mathrm{ECE}=$ Embryonating chicken eggs;

HA = Hemagglutinin;

$\mathrm{ELD}_{50}=$ Embryo lethal dose $50 \%$. 